\title{
Making sense of urban food festivals: cultural regeneration, disorder and hospitable cities
}

Paper accepted for publication in the Journal of Policy Research in Tourism, Leisure and Events February 2014

\section{Authors:}

Joanne Hollows (School of Arts \& Humanities, Nottingham Trent University, Clifton Lane, Nottingham NG11 8NS)

Steve Jones (School of Arts \& Humanities, Nottingham Trent University, Clifton Lane, Nottingham NG11 8NS. Tel: 0115 8483222. Email: steven.jones@ntu.ac.uk)

Ben Taylor (School of Arts \& Humanities, Nottingham Trent University, Clifton Lane, Nottingham NG11 8NS. Tel: 0115 8483033. Email: ben.taylor@ntu.ac.uk)

with Kimberley Dowthwaite (undergraduate student (from 2008-11) in the School of Arts \& Humanities, Nottingham Trent University, Clifton Lane, Nottingham NG11 $8 \mathrm{NS})$ 


\section{Abstract:}

This article examines urban food festivals, and in doing so it carries out a case study of Nottingham's Food and Drink Festival (NFDF). It contends that such festivals need to be understood in relation to local contexts, such as the reputation for alcoholrelated disorder associated with Nottingham's night-time economy. Rather than being used to attract tourism, NFDF was primarily directed at existing residents of Nottingham, where it sought to produce particular kinds of guests who would be able to invest in the city's wider regeneration. Here, the article draws on recent academic work on hospitality in demonstrating how NFDF attempted to rebrand the city centre as a more hospitable place. It concludes by showing how visitors to NFDF exhibited a sense of generosity and pride, and argues that the meaning of urban food festivals cannot therefore simply be reduced to the logic of neoliberal governance.

Keywords: food festivals, urban tourism, cultural policy, night-time economy, hospitality. 


\section{Making sense of urban food festivals: cultural regeneration, disorder and hospitable cities}

Food festivals have become an increasingly visible part of local and regional calendars in the UK. Existing research has tended to focus on food festivals located in rural areas and/or tourist destinations, and to address them in relation to a series of policy initiatives around the future of rural economies alongside an emergent valorization of local food cultures (Hall \& Sharples, 2008). In this article we turn our attention to the urban food festival, focusing on a case study of Nottingham Food and Drink Festival (NFDF). While the rapid proliferation of urban food festivals in the UK has led some commentators to describe them as indistinguishable, we argue that such a view ignores the specificities of place. We suggest instead that food festivals need to be located in relation to local cultural policy objectives. In the light of this, we demonstrate that NFDF was a response to a series of specific concerns about urban disorder and Nottingham's negative place image. We conclude by considering how NFDF, despite its origins in commercial interests and city centre management, nevertheless broached questions of hospitality and cultural citizenship. Our study responds to the call for 'greater interdisciplinarity' in 'the field of festival studies' (Getz, 2010: 1) by synthesizing approaches derived from food studies and from analyses of both urban disorder and the night-time economy (NTE). In this way, our research contributes to a developing problematization of urban reimaging processes (Bavinton, 2010). By demonstrating how notions of urban hospitality are not only mobilized by local governance, but lived and understood by city residents, we also nuance accounts of the hospitable city and the role of local people as 'hosts' (Bell, 2007b; Richter, 2010).

Before moving on to explore these issues, it is necessary to introduce some of the key characteristics of NFDF. Our research focused on the second annual NFDF, a four-day festival in late September 2010. The event was organized and largely funded by We Are Nottingham, the Business Improvement District (BID) which represents 'leisure businesses' (primarily hospitality providers) in a tightlydemarcated area of the city centre. While NFDF offered BID members opportunities 
to promote their own eating and drinking venues, it was also conceived of as a means of redefining the meaning of the city centre as a food and drink space and attracting a wider cross-section of people to participate in the evening and nighttime economies.

Our focus on NFDF in this article is part of a wider project in which we analyzed the extent and diversity of food and drink festival activity across the UK in summer 2010. The first phase of this project was a qualitative analysis of publicity materials compiled by an undergraduate researcher, Kimberley Dowthwaite, as part of Nottingham Trent University's Scholarship Projects for Undergraduate Researchers. As our research proceeded, we became particularly interested in the local policy dimensions of such events, and this shaped the direction of our empirical investigation of NFDF. Prior to the event, two researchers conducted an in-depth interview with Sylvia Manser, the Chief Executive of We Are Nottingham. However, the bulk of our research was carried out by all four researchers during the course of the four-day event. First, we conducted over 70 semi-structured interviews with visitors to the festival, many of which took place in the hospitality tent, where people had the opportunity to sample free food. This enabled us to understand people's motivations for attending the festival, the meanings they brought to it, and their accompanying perceptions of Nottingham. Second, we recorded a series of discussions with stallholders at the event, some of whom were food vendors, others of whom represented the hospitality industry in Nottingham. These discussions particularly focused on the relationship between local forms of governance, Nottingham's place image and economic activity. Third, we observed the festival over its duration in order to understand its dynamics and rhythms, participating in a series of events including four celebrity chef demonstrations and activities hosted by local restaurants. While the findings from this research are used throughout the course of the article, in the final section we draw more extensively on our interviews with visitors to the festival in order to develop an analysis of how the festival contributed to ideas of the hospitable city. 
Although various activities took place across the city centre, the focus for the event was Nottingham's Old Market Square, where a central marquee was divided into a 'Hospitality Area', offering a rolling programme of free samples from city eating places, and a large 'Celebrity Chef Theatre', partly sponsored by high-end supermarket Waitrose, which hosted a series of ticketed events for a fee. There was also a smaller 'Demonstration Theatre' which featured a series of free events largely offered by local food and drink providers. Surrounding these marquees were over thirty stalls, representing both local independent ventures and national chains with a presence in the city centre. Some of these offered food samples and dishes to buy from local cafes and restaurants, while others offered opportunities to purchase goods from local producers and food-related retailers. As a whole, the event offered a bustling, market-like feel to visitors, punctuated by the presentations and demonstrations taking place during the day. The local media reported that 25,000 visitors attended over the course of the festival, a 30 percent increase on the figure for the previous year (This is Nottingham, 2010).

The location of the festival in the Old Market Square - Nottingham's central space and symbolic heart - is significant to our analysis. The square has a long history both as a site of commerce and trade and as a site for local events. Indeed, it was the location for the city's most famous annual event, Goose Fair, which shifted from being an agricultural fair to a popular carnival associated with 'disreputable pleasures' prior to its relocation in 1928 . When the square was subject to its most recent major redevelopment between 2004 and 2007 to enhance its status as 'a great public space' (Nottingham City Council 2005: 20; see also Heath 2010), the historical meanings of the site were acknowledged by the developers. As well as seeking to animate the city's defining space with a sequence of events, the developers recognized 'the original reason for the square's existence by enabling it to be used as a market place' (BBC, 2004).

This type of festival was not unique to Nottingham and there were events with some similar features taking place in other British cities that year. Although demonstrations both by Nottingham's Michelin-starred chef, Sat Bains, and by 
Johnny Putzai, a celebrated local butcher, partially anchored these events in locality, the presence of TV chefs who were doing the food festival circuit around the country led the Guardian newspaper to describe NFDF as 'generic' (Majumdar, 2009). However, as we go on to explore, not only are there other significant features of these urban food festivals beyond their apparent standardization but also NFDF needs to be understood as a response to a distinctively local constellation of factors. As Kierans and Haeney (2010: 102) argue, 'while the commodification of local identities, practices and goods has been articulated' in a wide range of 'regenerating' cities, 'rather than producing generic or universal effects, these are, instead, social processes, whose logics are differentially played out within cities'.

NFDF belonged to a sequence of events and spectacles staged in Market Square throughout the year, and usually contracted out to private enterprise, including an ice rink, an urban beach, a big wheel and a giant illuminated carousel. As David Bell (2009: 3) has argued, while such events 'might be seen as a form of "entrepreneurial display" - the use of spectacles in the service of promotional urban governance' - we also need to think about how people use them to produce forms of urban sociality that might not straightforwardly service the aims of urban governance. As we go on to argue in the final section, where we examine theories of hospitality, NFDF enabled modes of urban hospitality and cultural citizenship that may not always coincide with interests of the neo-liberal city. Before doing this, however, we locate NFDF within some of the existing research into food, promotion, regeneration and place identity.

\section{Regeneration, place and food festivals}

If British cities have increasingly sought a form of 'urban entrepreneurialism', revolving around 'public-private partnerships, place-marketing and arts-led regeneration' (Quilley, 2000: 601), then urban festivals have become a resource for projecting 'an alluring image to potential residents, investors and visitors' (Bradley \& Hall, 2006: 77). Indeed, the tourism website for Nottinghamshire presents Nottingham as a 'city of festivals', suggesting that 'you'll usually find somewhere in the city that is in full festival swing' (Experience Nottinghamshire, 2011). Festivals 
have therefore become 'increasingly written into civic cultural policies as both product and framework, designed to attract a wealthy target market and furnish the city with a competitive image' (Jamieson as cited in Johansson \& Kociatkiewicz, 2011: 393).

In the UK, research on food festivals and regeneration has largely focused on the role of food in producing a distinctive and 'authentic' sense of place in rural locations and/or tourist destinations. While this perspective is undoubtedly relevant to highprofile British food festivals such as those located in Abergavenny and Ludlow (see Sharples \& Lyons, 2008), in this section we argue that it is not easily applicable to NFDF or urban food festivals more generally. Indeed, the proliferation of food festivals in the UK can be partly attributed to a series of policies in the 2000s that sought to use food in a wider process of boosting and regenerating rural areas, policies that were, in part, a response to the 2001 outbreak of foot and mouth disease. These policies included attempts to reconnect food producers and consumers, diversify agricultural economies and to enhance economic, social and environmental sustainability (Countryside Agency, 2002; Policy Commission on the Future of Farming and Food, 2002), frequently emphasizing the importance of sustainable tourism to rural regeneration. Overlapping with this policy dimension, a broader, critical discourse of 'local food systems' (Anderson \& Cook, 2000: 237) has emerged, which looks to rebalance the relationship between local and distant supply by the creation of farmers' markets and food fairs. Such moves, it has been claimed, can variously strengthen the local economy, limit the role of commercial intermediaries, revitalize communities, produce fresher and healthier food, combat urban sprawl, foster a sense of place and generate environmental benefits (Buck et al., as cited in Hall \& Sharples, 2008).

While rural food festivals were peripheral to the concerns of these initial policy initiatives, they have nonetheless emerged as a means of addressing some of these issues. Not only do festivals offer opportunities to connect both locals and tourists to food producers and act as events which can draw in tourists, they also enable tourists to be educated and informed about the produce associated with a town or 
region and enable produce to be used to promote place identities (see Everett \& Aitchinson, 2008 and Adema, 2009). Although such festivals may attempt to construct a food-based place identity for residents as well as tourists, NFDF was primarily designed to attract residents of the city and its surrounding areas and this has an impact on how festivals contribute to associations between hospitality and place.

The limited importance of produce to Nottingham's place image at the 2010 NFDF is exemplified by the ambiguously titled 'local and regional Food and Drink Market' which ran throughout the festival. If 'local' is equated with the city itself, then it was primarily represented by city restaurants offering food samples (usually for a small fee) and, to a lesser extent, by city food and drink retailers such as The Cheese Shop, Delilah delicatessen, Lee Rosy's tea and Somersby Chocolates (of whom only the last highlighted Nottingham produced goods). Regional produce was better represented in the form of producers such as Thorpe Latimer Traditional Farm Meats (from Lincoln), the Nottinghamshire based Welbeck Farm Shop, and Moden's Lincolnshire Plum Bread Company. Therefore, although the festival did provide a showcase for some produce associated with the East Midlands, frameworks for understanding food festivals in terms of a close relationship between food products and place identity seem to have little relevance to NFDF.

Furthermore, unlike some other cities in the UK, Nottingham is not associated with particular food items or dishes: there is no local equivalent of Liverpool's scouse or Birmingham's balti which have been mobilized in place promotion strategies as the basis for urban regeneration (Kierans \& Haeney, 2010; Ram, Abbas, Sanghera \& Hillin, 2000;). Although NFDF was centred around the city's eateries, then, there were no distinctive features that helped to create a unifying brand for some or all of these restaurants. This contrasts with urban food festivals such as Brick Lane's annual Curry Festival which is organized by local restaurateurs (Frost, 2011). It also contrasts with cities who incorporate distinctive ethnic eating quarters within their place-branding schemes: despite a wide variety of 'ethnic' restaurants in the city, 
there are no 'Chinatowns' or 'Little Italys' in Nottingham, nor is there an 'Indian' restaurant cluster equivalent to Manchester's Rusholme or Leicester's Golden Mile.

There is thus very little in terms of produce, dishes or distinctive eating quarters around which to brand Nottingham in terms of a culinary identity or as a culinary destination for tourists. Instead, the organizers of NFDF aimed to promote the 'variety' of eating out experiences in the city - a view bolstered by Sylvia Manser's bold claim that the city has 'the greatest variety of food offerings outside London' (quoted in Tresidder, 2009) - and the term 'variety' was repeated as a positive feature of both the festival and the city by nearly half of our interviewees attending the event. However, while local governance clearly has an understanding of the ways in which 'urban culinary culture can play a paramount role in producing the habitat for ongoing regeneration, and also provides a powerful symbolic statement about urban fortunes' (Bell \& Binnie, 2005: 80), the strategies deployed in NFDF to realize these messages are primarily addressed to Nottingham (and Nottinghamshire) residents rather than gastro-tourists or global capital. Indeed, as we go on to suggest, the strategies implemented in NFDF were aimed at producing particular kinds of guests with the cultural and economic assets that would enable them to invest in - and act as ambassadors for - both Nottingham's culinary culture and its wider regeneration.

\section{Food, drink and regulating disorder}

If Nottingham has no clearly-defined identity as a food destination, it has an often unwelcome reputation as a drinking place, and in this section we argue that a key context for thinking about NFDF is the centrality of this reputation to Nottingham's place image. The rationale for the festival - and the nature of its funding - can be located in a series of local and national policy initiatives stretching back to the mid1980s. Despite its traditional characterizations as the 'Queen of the Midlands', regional capital of the English East Midlands (as part of a 'three-city region' which also includes the cities of Derby and Leicester), and a self-consciously 'modern' city (Daniels and Rycroft, 1993), Nottingham has suffered from the removal of its urban industries, and from the deindustrialization of its semi-rural hinterland. In spite of 
this, with a large student population, the city has a long-standing reputation as the nightlife and consumption centre of the region. Capitalizing on this, Nottingham's city authorities made repeated attempts to re-brand the city centre in the hope of creating a more positive image among both locals and outsiders by presenting an image of Nottingham as a 'great European city' (Experience Nottinghamshire, 2007). The notion of 'Europe' here - based like so many other regeneration policies on the examples of Barcelona (Department of Culture, Media and Sport, 2004) and Glasgow, Manchester and Bilbao (Rousseau, 2009) - is a highly selective one of cool, heterogeneous cosmopolitanism, as opposed to the 'monoculture' of young, straight and primarily male drinkers (Oc \& Tiesdell, 1998: 97) who were felt to dominate both the place image and night-time economy of Nottingham.

Central to these strategies was an attempt to 'broaden the evening economy' by extending shop opening hours and creating incentives to encourage workers and shoppers to stay in the city to eat or go to the cinema (Oc \& Tiesdell, 1998: 97). These initiatives attempted to increase and diversify the city's evening and nighttime populations and attract a greater number of older people in order to 'crowd out' disorder (and, in particular, although their class was unspoken, to entice middleclass women into the evening and NTE). As part of this diversification strategy, a rhetoric developed around the importance of a European-style 'café culture' in promoting urban regeneration.

While the (limited) growth of 'cosmopolitan' café-bars offers one narrative about Nottingham's NTE, it is not the only narrative. As Hobbs, Hadfield, Lister and Winlow (2005: 28) note, 'whilst a "sophisticated and mixed economy [featuring] elegance, variety and refinement" may constitute the planning professional's ideal, the reality is that the night-time economy is largely an unregulated zone of quasi-liminality awash on a sea of alcohol'. In Nottingham, the weakening of magistrates' licensing powers after 1996 seemed to contribute to the growth of 'vertical drinking establishments' providing high-volume 'drinkatainment ' (Bell, 2007a) for a predominantly youthful clientele. Furthermore, while some towns and cities saw a fall in recorded violent crime after the 2003 Licensing Act extended drinking hours, 
Nottingham saw a $12 \%$ increase in these crimes in the year following its implementation, including a rise in violence between $11 \mathrm{pm}$ and midnight (Hough \& Hunter, 2008: 252). Anxieties about Nottingham's leading role in the de-regulation of the NTE and its attendant surge in disorder were given further publicity when the BBC's Panorama series documented three months in the city during 2004. Amid images of violence, 'binge-drinking' and out-of-control bodies, the programme argued that 'Nottingham has played a defining role in the story of [the night-time] economy.'

While the legalization of longer drinking hours was frequently seen to work in the interests of a drinks and leisure industry that had lobbied hard for de-regulation (Hadfield, 2006), the 2003 Licensing Act was also accompanied by extensive forms of re-regulation to prevent crime and disorder, promote public safety and protect children from harm. As a result, the Act 'inserted the control of alcohol into the heart of urban governance' (Hadfield, Lister \& Traynor, 2009: 466). In Nottingham, some of the Act's statutory objectives were met through self-regulation, since licensees routinely sign up for the national accreditation scheme Best Bar None, and the crime prevention scheme Pub Watch.

However, the development of NFDF also needs to be understood as a reflexive response to the increased authority allocated to the police under the Act. Using data that showed large increases in both the capacity for drinkers in city-centre bars, and in violent crime and public disorder offences, the police successfully recommended that the local authority label the city centre as a 'cumulative impact area' or 'saturation zone'. This gave the police greater influence in the rejection of applications for new licensed premises in the city centre. Furthermore, the police engaged in a protracted clampdown on businesses breaching rules around the sale of alcohol (particularly to underage drinkers) leading to revocations of licenses (Anderson, 2011; Lucas, 2011; Read, 2011). However, rather than helping Nottingham's place image, some commentators claimed that these moves had a negative impact on the city: instead of 'crowding out' disorder, re-regulation threatened Nottingham's reputation for vibrant nightlife. 
Whether intentionally or not, this coercive use of police powers had the effect of redirecting the governance of drinking in the city centre back towards licensees. The appearance of Business Improvement District regulations in 2004, dedicated to creating a 'safer trading environment', aimed to put responsibility for the control of disorder back in the hands of licensees, since 'it is the fee-payers, rather than the regulatory authorities, who establish and control the initiative' (Hadfield et al., 2009: 477). Nottingham's BID scheme became the first dedicated purely 'to the needs and priorities of the night-time economy' (ibid.). Licensees voted in 2009 for the establishment of the BID for which they must pay a mandatory $1.5 \%$ of their rateable value, generating $£ 250,000$ a year up to 2014 .

The aims of NFDF therefore seemed to fall clearly within this private-sector led version of urban revitalization. While We Are Nottingham funds a city centre taxi marshalling scheme, it also funds other initiatives which aim to attract people into the city centre and to diversify the nature of night-time leisure (such as Big Night Out, in which restaurants, cafes and bars put on offers, and an illuminated nighttime arts event called Light Night). In an interview, Sylvia Manser noted that 'One of the key things is to bring in other groups of people for whom [drinking to excess] is not the main objective. A wider demographic of people might be self-policing.' With its funding from the licensed trade, NFDF could hardly be puritanical around alcohol. Instead it performed its own version of 'crowding out' by linking food with drink (it is not, as it could have been, the Nottingham Food Festival) and by attempting to diversify drinking behaviour by organizing, for example, wine-tasting events and cocktail classes as part of the festival.

The management of Nottingham's NTE, therefore, suggests we need to consider a variety of contexts and forms of change when accounting for the appearance and form of the NFDF. On the one hand, there is certainly an attempt to reshape the NTE through the imposition of statutory powers and the levering in of private-sector funding to augment the cost of policing it. But rather than being simply a partnership with the police and local authority, the BID also represented a critical voice. As 
Manser points out, 'Licensees can expect us to lobby the police and local authority, especially if they are trying to impose unreasonable licensing conditions. We can also act as a mediator between the police, the council and licensees' (as quoted in Tressider, 2009). Our discussion might also suggest another neo-liberal logic at work in which the licensed trade competes for the high-end consumers currently intimidated by the violence associated with Nottingham's NTE, seeking to provide venues 'capable of attracting the middle classes in search of "distinction"' (Rousseau, 2009: 785). But while these logics capture some of the imperatives behind the festival, they fail to account for the specificity of the stalls and events, some of which were concerned with less 'distinguished' forms of food. Nor do they account for the role of visitors to the event, and their part in producing its meanings. It is to this that we now turn.

\section{Creating a hospitable city?}

Recent work on hospitality offers another way of understanding the policy initiatives associated with NFDF. In this section, we want to think about the event as a strategy for building Nottingham's reputation as a hospitable city, particularly in the light of media coverage whose focus on violence and binge-drinking characterized the city as distinctly inhospitable. In the process, we examine how urban food festivals may act as a means of promoting more hospitable cities.

In his work on the hospitable city, Bell (2007a: 7) argues that 'certain versions of hospitality (and hospitableness)' have become central to strategies of 'urban regeneration, place promotion and civic boosterism' that are frequently based around engineering identities for cities as spaces of consumption. Following Sharon Zukin (1995), food and drink spaces have often been thought of as an important constituent of culture-led regeneration, where they are seen as 'part of the social and economic processes through which [...] urban areas are transformed into gentrified, aestheticized playscapes for an affluent new middle class' (Lugosi, Bell \& Lugosi, 2010: 3079). 
Nottingham has in some ways conformed to this strategy of combined culture- and gastronomy-led regeneration. The development of a 'cultural quarter' in the Hockley and Lace Market area of the city, for example, has undoubtedly provided a new middle-class playscape (see Shorthose, 2004). However, it has also been susceptible to the intrusions of undifferentiated national restaurant and pub chains with, in some cases, the violent disorder that accompanied this transformation.

We Are Nottingham is certainly alert to the idea that a 'creative quarter' strategy can act as an incubator for consumer dispositions, and in 2010 helped to fund a music festival in the quarter, the Hockley Hustle. But it was noticeable that, despite the programme of dispersed food and drink events around the city centre, NFDF was overwhelmingly concentrated in the Old Market Square and its roster of stalls run by local food providers pulled the creative quarter into the city centre. While this was, in part, a consequence of needing to house the celebrity chef events, it also concentrated visitors to the festival in its symbolic and geographical centre and performed, temporarily, the act of mixing people across class, age, gender and ethnic lines. Rather than hospitality being associated with a specific place within the city, therefore, there was an attempt to make Nottingham as a whole hospitable. This took the form both of top-down attempts to remake Nottingham people as 'ambassadors for the city' but also visitors' own efforts to re-enchant themselves with the city through the cultivation of a disposition of 'festive sociality'(Bell, 2009). We look at these strategies and tactics now.

A key theme in some theories of hospitality has been the ways in which hospitality is a means of 'managing the stranger who represents a potential for danger [...] and is civilized through the process of providing hospitality, which facilitates the development of relationships' (Lynch, Germann Molz, McIntosh, Lugosi \& Lashley, 2011: 6). However, as we have already suggested, NFDF needs to be understood in terms of other strategies of governance. The festival was not aimed at outsiders and 'strangers' and was not conceived of primarily as a tourist event, even if a boost to tourism was a welcome side-effect. Instead, the aim was to woo back specific types of 'locals' who had become 'strangers' to the city at night because they disidentified 
with its image as a drinking space. As our interviews reveal, a good number of those who attended the NFDF shared these anxieties. One couple, for example, spoke of having to 'steel themselves' to come to Nottingham in the evening, while another participant explained that they didn't like being in the city at night.

By articulating food and drink, the festival not only associated the night-time city with restaurants as well as pubs, it also sought to reimagine the meaning of drink by focusing on potentially more middle-class forms of alcohol consumption. This was achieved through events such as 'cocktail masterclasses' and a Wine Night at the Fat Cat Café Bar, wine-tasting events hosted by the wine retailers Oddbins and Majestic, cheese and wine tastings at Tonic Bar and Restaurant and a session on 'Beer and Food matching' in at the Kean's Head pub. However, a key focus of the festival was on the city's eating spaces, promoted not only through market stalls but through a series of sessions in the Demonstration Theatre, free samples in the Hospitality Area, various events located in the city's restaurants such as special 'gourmet' and 'charity' dinners and an extensive range of discounts at cafes and restaurants which were promoted within the festival's programme.

These events were clearly marketing opportunities for individual eating places within the city centre. At the same time, however, they were joint initiatives through the BID, whose aim was to 'temporalize the centre' (Hughes, 1999: 128) by promoting the area as a night-time eating space. By encouraging middle-class and no longer young consumers to eat in the city centre, the event not only attempted to boost the NTE in general but to shift its basis away from drink. Therefore, rather than offering hospitality in an attempt to 'civilize' those 'others' (in particular, young working-class men) who were seen as damaging to the city's reputation, the strategy was to offer a 'selective welcome' (Bell, 2007b: 33) to types of guests who might enhance the city's reputation, diluting the impact of those 'others' on the city's image. As Young, Diep and Drabble (2006: 1692) argue, such 'reimaging practices' in place promotion 'play a role in "naturalizing" visions of city-centre regeneration along "correct" or "accepted" lines. As they define, legitimate, naturalize and promote what is "normal" in the city, they also define "unacceptable" difference'. In this way, the 
selective welcome offered to potential 'legitimate' consumers also works to reinforce the illegitimacy of those consumers who are currently associated with the city's NTE.

However, while NFDF was viewed by its organisers as fulfilling a number of specific objectives, we would argue that, even when viewed in policy terms, festivals can't simply be reduced to the social and economic functions that they perform. As Colin Hall (1992: 65) notes in his study of 'hallmark events', we shouldn't lose sight of 'the less tangible costs and benefits' of such practices. In this respect, as Çela, KnowlesLankford and Lankford (2007: 172) suggest, food festivals might be used to foster some of the very processes with which food consumption itself is associated: 'relaxation, communicating with others, learning about new things, and hospitality'.

Although the festival sought to extend a welcome to specific local guests - and more generally to create "longer term "legacy benefits" that... badge the city as hospitable long after the event' (Bell, 2007b: 32) - these guests can also be thought of as potential hosts who themselves contribute to the hospitableness of the city in the longer term. For Bell (2007b: 38), city occupants are engaged in 'mundane, takenfor-granted, fleeting' performances of hospitality, whether these are passing interactions at stalls or in the hospitality area at the festival itself, or in transitory moments of exchange between diners in a restaurant at a later time. On one level, then, we can read NFDF as an attempt to attract consumers of the NTE who will act as 'respectable' hosts as well as 'respectable' guests (Banister, Fyfe \& Kearns, 2006), aiming to reimage Nottingham as a 'respectable' hospitable city and move away from its associations with more disreputable forms of hospitality.

This use of local participants as a citizenly resource, rather than just a group of consumers-in-waiting, resonates with Jim McGuigan's analysis of the 'visitor experience' of the Millennium Dome, in which he observes that the 'major coordinates of visitor orientation' are 'generosity and reflexivity' (McGuigan, 2004: 88). We can develop these insights further in relation to some of the data recorded in our empirical research. In the section below, we give snapshots of the key phrases 
used by a range of our respondents in the longer interviews while articulating their experiences of the festival. Several of our interviewees recognized that there is little that is locally specific about Nottingham city centre and that its food and dining opportunities consist largely of 'cosmopolitan', 'chain' and 'not very local' places to eat and drink. However, rather than feeling ill at ease in this 'logoscape' (McGuigan, 2004: 89), they typically enacted a generosity of spirit about Nottingham which they saw as standing in opposition to consistently negative media representations of it as 'the worst or second worst city in the country', which 'gets bad press' as a place of 'shootings and crime'.

In contrast, many respondents understood Nottingham as a place 'on the up', which was 'developing and improving' in a good way as a 'vibrant', 'multicultural' city. When asked about the city's image, a number of interviewees volunteered comments about how it was 'entertaining', had 'a lot going on', 'lots of free events', and 'a lot happening culture and art-wise'. While these responses are perhaps unsurprising considering that these people were attending such an event at the time, other respondents took the opportunity to elaborate on their feelings about public events. One family talked positively about Nottingham's Big Night Out suggesting it was a way of bringing generations closer together, with the daughter commenting 'I didn't want to go home'. The same family also talked positively about the summer's creation of an urban beach in the Market Square, suggesting it was a way of 'treating' children who otherwise wouldn't get a holiday. This suggests that place promotion strategies cannot be read simply in terms of consumption-led regeneration and exclusion (see Jones \& Wilkes-Heeg, 2004 and Mooney, 2004), and that a broader understanding of hospitality allows us to make sense of the reflexive generosity of those who take part in such events. While McGuigan's analysis of the Millennium Dome concluded that there was a sense of 'disappointment' (McGuigan, 2004: 90) on the part of its visitors, we found a more active reclamation of urban citizenship associated with the NFDF.

\section{Conclusion}


Festivals such as NFDF present a challenge to existing approaches to discussing the significance of food festivals which have tended to focus on issues such as rural regeneration and/or tourism in relation to place identities. Although our study is informed by ideas from this literature, we have gone on to demonstrate how the increasing importance of urban food festivals not only needs to be understood in terms of cultural policy but in terms of wider debates about urban regeneration and place identity. Furthermore, while urban food festivals in the UK have been characterized as 'generic', we have suggested that attending to the specificities of place offers a more useful approach to understanding their significance. The context of a place image bound up with drunk and disorderly behaviour provides a key route to understanding the 'civilizing' role envisaged for NFDF in the management of Nottingham.

Literature on urban regeneration tends to concentrate on top-down initiatives such as gentrification by capital and entrepreneurial spectacles. Although an understanding of such processes is essential in making sense of contemporary city governance and culture, studies of urban culture also need to pay attention to dispositions of the city's residents whose everyday practices are caught up with these phenomena. Just as the 'generosity', the local pride and the hospitable dispositions of participants in urban food festivals are not simply stage-managed by festival organizers, so the meaning of urban food festivals cannot simply be reduced to the logic of neo-liberal governance. Indeed, by drawing on recent debates about hospitality and urban citizenship we hope to nuance accounts of urban culture which see it simply as an expression of a neo-liberal logic.

\section{Acknowledgements}

The authors are grateful to Nottingham Trent University's SPUR (Scholarship Projects for Undergraduate Researchers) scheme for supporting the research carried out for this article. 


\section{References}

Anderson, J. (2011, 11 January). How the changes in licensing laws transformed Nottingham's nightlife. Nottingham Evening Post.

Retrieved from http://www.thisisnottingham.co.uk/Years-stagnationled-floodgates-opened-new-generation-city-bars/story-12179812detail/story.html.

Anderson, M.D. \& Cook, J. (2000). Does food security require local food systems?. In J.M. Harris (Ed.), Rethinking sustainability: Power, knowledge and institutions (228-248). Ann Arbor: University of Michigan Press.

Adema, P. (2009). Garlic capital of the world: Gilroy, garlic and the making of a festive foodscape. Jackson: University Press of Mississippi.

Banister, J., Fyfe, N., \& Kearns, A. (2006). Respectable or respectful? (In)civility and the city. Urban Studies, 43, 919-37. doi: 10.1080/00420980600676337.

Bavinton, N. (2010). Putting leisure to work: city image and representations of nightlife. Journal of Policy Research in Tourism, Leisure and Events, 2, 236-250. doi: 10.1080/19407963.2010.512206.

BBC (2004). Old Market 'Square Design'. Retrieved from http://www.bbc.co.uk/nottingham/features/2004/03/old market square des igns gustafson porter.shtml.

Bell, D. (2009). Winter wonderlands: Public outdoor ice rinks, entrepreneurial displayand festive socialities in UK cities. Leisure Studies, 28, 3-18. doi: $10.1080 / 02614360802260952$.

Bell, D. (2007a). The Hospitable city: Social relations in commercial space. Progress in Human Geography, 31, 7-22. doi: 10.1177/0309132507073526.

Bell, D. (2007b). Moments of hospitality. In J. Germann Molz \& S. Gibson (Eds.), Mobilizing hospitality: The ethics of social relations in a mobile world (29-46). Aldershot: Ashgate.

Bell, D. \& Binnie, J. (2005). What's eating Manchester? Gastro-culture and urban regeneration. Architectural Design, 75, 78-85. doi: 10.1002/ad.80 
Bradley, A. \& Hall, T. (2006) The festival phenomenon: Festivals, events and the promotion of small urban areas. In D. Bell \& M. Jayne (Eds.), Small cities: Urban experience beyond the metropolis (77-90). London: Routledge.

Çela, A., Knowles-Lankford, J. \& Lankford, S. (2007). Local food festivals in Northeast lowa communities: A visitor and economic impact study. Managing Leisure, 12, 171-190. doi: 10.1080/13606710701339470.

Countryside Agency (2002). Eat the view: Promoting sustainable local products. Wetherby: Countryside Agency Publications.

Department of Culture, Media and Sport (2004). Culture at the heart of regeneration. London: DCMS.

Daniels, S. \& Rycroft, S. (1993). Mapping the Modern City: Alan Sillitoe's Nottingham Novels. Transactions of the Institute of British Geographers, 18, 460-480. Retrieved from http://onlinelibrary.wiley.com/journal/10.1111/(ISSN)1475$\underline{5661 / \text { issues. }}$

Everett, S. \& Aitchinson, C. (2008). The role of food tourism in sustaining regional identity: A case study of Cornwall, South West England. Journal of Sustainable Food Tourism, 16, 150-67. doi: 10.2167/jost696.0.

Experience Nottinghamshire (2011). Festivals. Retrieved November 16, 2011, from http://www.experiencenottinghamshire.com/things-to-do/culture/festivals.

Experience Nottinghamshire (2007). A great European city. Retrieved March 9, 2007, from http://aboutus.experiencenottinghamshire.com/.

Frost, N. (2011). Green curry: Politics and place-making on Brick Lane. Food, Culture and Society, 14, 225-242. doi: 10.2752/175174411X12893984828791.

Getz, D. (2010). The nature and scope of festival studies. International Journal of Event Management Research, 5, 1-47. Retrieved from http://www.ijemr.org/index.html?page=25580.

Hadfield, P. (2006). Bar wars: Contesting the night in contemporary British cities. Oxford: Oxford University Press.

Hadfield, P., Lister, S., \& Traynor, P. (2009). This town's a different town today: Policing and regulating the night-time economy. Criminology and Criminal Justice, 9, 465-85. doi: 10.1177/1748895809343409. 
Hall, C.M. (1992). Hallmark tourist events: Impacts, management and planning. London: Belhaven.

Hall, C.M. \& Sharples, L. (Eds.) (2008) Food and wine festivals and events around the world: Development, management and markets. Oxford: Elsevier.

Heath, T, (2010). Nottingham: 'A consistent and integrated approach to urban design'. In J. Punter (Ed.), Urban Design and the British Urban Renaissance (pp. 148-164). Abingdon: Routledge.

Hobbs, R., Hadfield, P., Lister, S. \& Winlow, S. (2005). Violence and control in the night-time economy. European Journal of Crime, Criminal Law and Criminal Justice, 13, 89-102. doi: 10.1163/1571817053558310.

Hough, M. \& Hunter, G. (2008). The 2003 Licensing Act's impact on crime and disorder: An evaluation. Criminology and Criminal Justice 8, 239-260. doi: $10.1177 / 1748895808092428$.

Hughes, G. (1999). Urban revitalization: The use of festive time strategies. Leisure Studies, 18, 119-135. doi: 10.1080/026143699374998.

Johansson, M. \& Kociatkiewicz, J. (2011). City festivals: Creativity and control in staged urban experiences. European Urban and Regional Studies, 18, 392-405. doi:_10.1177/0969776411407810.

Jones, P. \& Wilks-Heeg, S. (2004). Capitalising culture: Liverpool 2008. Local Economy, 19, 341-60. doi: 10.1080/0269094042000286846.

Kierans, C. \& Haeney, J. (2010). The social life of 'Scouse': Understanding contemporary Liverpool through changing food practices. Cultural Sociology, 4, 101-22. doi:_10.1177/1749975509356864.

Lucas, D. (2011, 9 February). Nottingham licensing policy needs tighter focus, says lawyer. Nottingham Evening Post. Retrieved at http://www.thisisnottingham.co.uk/Nottingham-licensing-policy-needstighter-focus-says-lawyer/story-12243811-detail/story.html.

Lugosi, P., Bell, D., \& Lugosi, K. (2010). Hospitality, culture and regeneration: Urban decay, entrepreneurship and the 'ruin' bars of Budapest. Urban Studies, 47, 3079-3101. doi: 10.1177/0042098009360236. 
Lynch, P., Germann Molz, J., Mclntosh, A., Lugosi, P. \& Lashley, C. (2011). Theorizing hospitality. Hospitality and Society 1(1), pp. 3-24. doi: 10.1386/hosp.1.1.3_2.

McGuigan, J. (2004). Rethinking Cultural Policy. Maidenhead: Open University Press.

Majumdar, S. (2009, 7 September). Food Festivals - the best and the rest. Guardian. Retrieved at http://www.guardian.co.uk/lifeandstyle/wordofmouth/2009/sep/07/foodfestivals-interactive-map?INTCMP=SRCH.

Mooney, G. (2004). Cultural policy as urban transformation? Critical reflections on Glasgow, City of Culture 1990. Local Economy, 19, 327-40. doi: 10.1080/0269094042000286837.

Nottingham City Council (2005). Nottingham City Centre Masterplan 2005-15. Retrieved from http://www.nottinghamcity.gov.uk/CHttpHandler.ashx?id=7137\&p=0.

Oc, T. \& Tiesdell, S. (1998). City centre management and safer city centres: approaches in Coventry and Nottingham. Cities, 15, 85-103. doi: 10.1016/S0264-2751(97)10016-6.

Policy Commission on the Future of Farming and Food (2002). Farming and food: $A$ sustainable future. London: Cabinet Office.

Quilley, S. (2000). Manchester first: From municipal socialism to the entrepreneurial city. International Journal of Urban and Regional Research, 24, 601-15. doi: $10.1111 / 1468-2427.00267$

Ram, M., Abbas, T., Sanghera, B. \& Hillin, B. (2000) 'Currying favour with the locals': Balti owners and business enclaves. International Journal of Entrepreneurial Behaviour \& Research, 6, 41-55. doi: 10.1108/13552550010323230.

Read, H. (2011, 24 February). City has moved on and venues that offer something different will survive and thrive. Nottingham Evening Post, 26-7.

Richter, A. (2010). Exploiting an 'army of friendly faces': Volunteering and social policy implications. Journal of Policy Research in Tourism, Leisure and Events, 2, 184-188. doi.: 10.1080/19407963.2010.482278.

Rousseau, M. (2009). Re-imaging the city centre for the middle classes: Regeneration, gentrification and symbolic policies in 'loser cities'. International 
Journal of Urban and Regional Research, 33, 770-788. doi: 10.1111/j.14682427.2009.00889.x.

Sharples, L. \& Lyons, H. (2008). Ludlow Marches Food and Drink Festival. In C. M. Hall \& L. Sharples (Eds.), Food and wine festivals and events around the world: Development, management and markets (pp. 101-112). Oxford: Elsevier. Shorthose, J. (2004). Nottingham's de facto cultural quarter: The Lace Market, independents and convivial ecology. In D. Bell \& M. Jayne (Eds.), City of quarters: Urban villages in the contemporary city (pp. 149-162). Aldershot: Ashgate.

This is Nottingham (2010, 5 October). Nottingham Food and Drink Festival attracts almost 25,000 visitors. Nottingham Evening Post. Retrieved from http://www.thisisnottingham.co.uk/Food-drink-festival-attracts-24-000/story12181330-detail/story.html.

Tresidder, R. (2009, 24 November). Business lunch: Sylvia Manser, Chief Executive, Nottingham Leisure BID. Nottingham Evening Post, 25.

Young, C., Diep, M. \& Drabble, S. (2006). Living with difference? The 'cosmopolitan city' and urban reimaging in Manchester, UK. Urban Studies, 43, 1687-1714. doi: $10.1080 / 00420980600888486$

Zukin, S. (1995). The culture of cities. Oxford: Blackwell. 